\title{
Determinants of changes in vitamin D status postpartum in Swedish women
}

\author{
Petra Brembeck*, Anna Winkvist, Mari Bååth, Linnea Bärebring and Hanna Augustin \\ Department of Internal Medicine and Clinical Nutrition, Institute of Medicine, Sablgrenska Academy, University of \\ Gothenburg, Box 459, SE-405 30 Gothenburg, Sweden
}

(Submitted 30 June 2015 - Final revision received 6 October 2015 - Accepted 15 October 2015 - First published online 20 November 2015)

\begin{abstract}
Low vitamin D status has been associated with unfavourable health outcomes. Postpartum, it is speculated that maternal vitamin D status decreases due to transfer of vitamin D from mother to child through breast milk. A few studies have investigated changes in maternal vitamin D postpartum and possible determinants. Thus, the aims of the present study were to determine changes in serum concentrations of 25-hydroxyvitamin D (25(OH)D) between 2 weeks and 12 months postpartum in Swedish women and to evaluate lactation and other determinants for changes in $25(\mathrm{OH}) \mathrm{D}$ concentration postpartum. In total, seventy-eight women were studied at 2 weeks, 4 months and 12 months postpartum. Data collection included measurements of weight and height as well as information about lactation, sun exposure, use of oestrogen contraceptives and physical activity level. Blood samples were collected and serum 25(OH)D levels were analysed using liquid chromatography-tandem MS. Dietary intake of vitamin D was recorded using 4-d food diaries. For all the women studied, mean serum 25(OH)D did not change between 2 weeks and 12 months postpartum (67 (SD 23) v. 67 (SD 19) nmol/l). No association was found between lactation and changes in serum $25(\mathrm{OH}) \mathrm{D}$ concentration postpartum. Significant determinants for postpartum changes in $25(\mathrm{OH}) \mathrm{D}$ concentration were use of vitamin D supplements $(P=0 \cdot 003)$, use of oestrogen contraceptives $(P=0 \cdot 013)$ and season $(P=0 \cdot 005)$. In conclusion, no changes were observed in $25(\mathrm{OH}) \mathrm{D}$ concentrations during the 1st year postpartum in these women and no association was found between lactation and changes in $25(\mathrm{OH}) \mathrm{D}$ concentration postpartum. The main determinants for the variation in changes in $25(\mathrm{OH}) \mathrm{D}$ concentrations postpartum were use of vitamin D supplements, use of oestrogen contraceptives and season.
\end{abstract}

Key words: Vitamin D: 25-Hydroxyvitamin D: Lactation: Postpartum

Low vitamin D status has been associated with unfavourable health outcomes in both infants and adults. Besides the wellknown effects of vitamin D on bone metabolism, low vitamin D status in adults has been associated with an increased risk of developing many chronic diseases ${ }^{(1,2)}$. In infants, low maternal serum concentrations of 25-hydroxyvitamin D (25(OH)D) during pregnancy have been associated with neonatal hypocalcaemia, osteopaenia and slow statural growth during the 1 st year of life ${ }^{(3)}$. At birth, infants' vitamin D status is totally dependent on maternal serum concentrations of vitamin $\mathrm{D}^{(1,3)}$. The vitamin $\mathrm{D}$ content of breast milk is also dependent on maternal serum $25(\mathrm{OH}) \mathrm{D}$ concentrations ${ }^{(1)}$, but the content in breast milk is low, between 0.1 and $3.4 \mu \mathrm{g} / \mathrm{l}$ of vitamin $\mathrm{D}$, depending on the season ${ }^{(4)}$. Changes in maternal vitamin $\mathrm{D}$ status postpartum and the role of lactation have been sparsely studied thus far.

The international recommendation from the WHO is for women to exclusively breast-feed their infants for the first 6 months postpartum, and to continue breast-feeding as a complement to solid foods until the child is 2 years of age or older $^{(5)}$. The Nordic Nutrition Recommendations are consistent with the WHO recommendations ${ }^{(1)}$. The definition of exclusive breast-feeding is that the infant is given no other food or liquids other than breast milk, with the exception of additional vitamins, minerals and medications ${ }^{(5)}$. During the first 5 months postpartum, Butte $\&$ King $^{(6)}$ reported mean production of breast milk to be $749 \mathrm{~g} / \mathrm{d}$ for women who were exclusively breastfeeding. For partial breast-feeding, the mean production of breast milk was $492 \mathrm{~g} / \mathrm{d}$ during the first 2 years postpartum ${ }^{(6)}$.

All the Nordic countries have relatively high breast-feeding prevalences $^{(1)}$. In Sweden, $81 \%$ of women exclusively breastfeed at 1 week postpartum and $96 \%$ breast-feed to some extent. Corresponding figures at 6 months postpartum are 15 and $63 \%$, respectively ${ }^{(7)}$. Given that women who are exclusively breastfeeding produce about $800 \mathrm{ml} / \mathrm{d}$ of breast milk and that they are breast-feeding for at least 6 months, the amount of vitamin D transferred from mother to child through breast milk during lactation may theoretically be large. This could have an impact on maternal vitamin D status. In Nordic countries, the recommended daily intake of vitamin D during lactation is the same as that for non-lactating women. This is because information about the association between vitamin D supplementation and health

Abbreviations: 25(OH)D, 25-hydroxyvitamin D; PAL, physical activity level.

* Corresponding author: P. Brembeck, email Petra.Brembeck@gu.se 
outcomes during lactation is limited and inconclusive ${ }^{(1)}$. Nevertheless, some suggest that there is increased maternal need for vitamin D during lactation ${ }^{(8)}$.

Sources of vitamin D are diet, dietary supplements and through cutaneous production after UVB exposure ${ }^{(2)}$. In Sweden, the major dietary sources of vitamin D are fish, dairy products and spreads ${ }^{(9)}$. According to a recent Swedish National Survey, the mean dietary intake of vitamin D among women is $6.4 \mu \mathrm{g} / \mathrm{d}^{(9)}$. The Nordic Nutrition Recommendation is a daily intake of $10 \mu \mathrm{g}$ of vitamin D in adults, also among lactating women, and considers some contribution of vitamin D from outdoor activities during the summer ${ }^{(1)}$. The recommendation from the Institute of Medicine (IOM) in the USA and Canada is higher $(15 \mu \mathrm{g} / \mathrm{d})$, because sun exposure is not included in this calculation $^{(10)}$. At northern latitudes, cutaneous production of vitamin $\mathrm{D}$ is not possible during winter, whereas below $35^{\circ}$ North cutaneous production of vitamin $\mathrm{D}$ is possible all year round $^{(11)}$. Besides latitude and season, skin pigmentation, sunscreen use, clothing, age, obesity, dietary intake and supplement use are reported to be determinants of serum concentrations of $25(\mathrm{OH}) \mathrm{D}$ among non-pregnant and nonlactating women ${ }^{(2,11-14)}$.

The optimal vitamin D status is a matter of debate. The IOM regards concentrations of $25(\mathrm{OH}) \mathrm{D}>50 \mathrm{nmol} / \mathrm{l}$ as sufficient to optimise $\mathrm{Ca}$ absorption and bone mineral density and to avoid rickets and osteomalacia ${ }^{(10)}$. This cut-off is also regarded as sufficient in the Nordic Nutrition Recommendations ${ }^{(1)}$. Concentration of $25(\mathrm{OH}) \mathrm{D}<30 \mathrm{nmol} / \mathrm{l}$ is regarded as deficiency, and concentration of $25(\mathrm{OH}) \mathrm{D}$ between 30 and $50 \mathrm{nmol} / 1$ is regarded as insufficiency ${ }^{(1,10)}$. Others have suggested that higher thresholds $(70-80 \mathrm{nmol} / 125(\mathrm{OH}) \mathrm{D})$ are necessary to reduce the risk of fractures $^{(15)}$.

Maternal vitamin D status during lactation has been sparsely studied thus far. Studies conducted on lactating mothers in Greece $^{(16)}$, Turkey ${ }^{(17)}$, Poland ${ }^{(18)}$, Shanghai ${ }^{(19)}$, Mexico ${ }^{(19)}$ and the $\mathrm{USA}^{(19)}$ in the early postpartum period have found mean concentrations of 25(OH)D between 27 and $70 \mathrm{nmol} / 1$, whereas a Swedish study conducted at 6-12 months postpartum observed serum 25(OH)D concentration of $53 \mathrm{nmol} / \mathrm{l}$ in Swedish-born women and $29 \mathrm{nmol} / 1$ in immigrant women ${ }^{(20)}$. There are very few studies on changes in maternal vitamin D status postpartum. A study from the United Arab Emirates observed a decrease in mean 25(OH)D during the first 6 months postpartum $^{(8)}$, whereas in a Danish study ${ }^{(21)}$ mean concentrations of 25(OH)D at both 2 weeks and 9 months postpartum were approximately $60 \mathrm{nmol} / 1$ and did not differ depending on breast-feeding status. In addition, Specker et al. ${ }^{(22)}$ observed no change in concentrations of $25(\mathrm{OH}) \mathrm{D}$ during the first 6 months postpartum in a study on lactating American mothers. Therefore, changes in vitamin D status postpartum have not been thoroughly studied and the results are inconsistent. In addition, the determinants of maternal vitamin $\mathrm{D}$ status postpartum, including lactation, have so far been scarcely studied.

The aims of this study were to determine the changes in serum concentrations of $25(\mathrm{OH}) \mathrm{D}$ between 2 weeks and 12 months postpartum in Swedish women and to specifically evaluate lactation and other determinants for changes in serum concentrations of 25(OH)D between 2 weeks and 12 months postpartum.

\section{Methods}

\section{Subjects}

A total of eighty-one women were enrolled to the study from July 2008 to July 2011 using posters in maternity healthcare clinics and in public places in the Gothenburg area, Sweden (lat $57-58^{\circ}$ North), and through an advertisement on a Swedish webpage addressing pregnant women in Western Sweden. For this analysis, the seventy-eight women who had data from the whole 1st year postpartum were included. Inclusion criteria for the study were as follows: women aged between 25 and 40 years, pregnancy at gestational week 35-37 at the start of the study and women who declared themselves as healthy. Exclusion criteria for the study were as follows: pregnancy during the last 1.5 years before the start of the present pregnancy, miscarriage after week 12 of pregnancy during the last 1.5 years, breast-feeding during the last year before the start of the present pregnancy, twin pregnancy and development of gestational diabetes or pre-eclampsia. This study was conducted according to the guidelines laid down in the Declaration of Helsinki, and all procedures involving human subjects were approved by the Regional Ethics Committee in Gothenburg. Written informed consent was obtained from all the women.

\section{Study design}

All women visited the Department of Internal Medicine and Clinical Nutrition, University of Gothenburg, Sweden, at baseline ( 2 weeks after delivery) and 12 months thereafter. Additional data were also collected at 4 months postpartum. At all visits, venous blood was drawn in the morning after an overnight fast, and body weight with only underwear (Tanita, BWB-800MA; Rex Frederiksbergs Vaegtfabrik) and height (standardised wall stadiometer) were measured. Information about lactation habits, use of vitamin D supplements and use of oestrogen contraceptives was also collected at all three visits. At baseline, women were further asked questions about their skin type and travels to southern latitudes. Information about smoking habits was collected at baseline and at 12 months postpartum. In addition, at 4 months postpartum, women were asked questions about sun preference. Four-day food diaries and information about physical activity level (PAL) were collected at 4 and 12 months postpartum.

\section{Methods}

Detailed information about lactation habits was collected from all lactating women, including number of lactation sessions per day, number and amount of formula feedings per day, date of introduction of solid foods and daily amount of solid foods given. Women were asked to record the date of their last lactation. Total lactation refers to any extent of lactation, and was defined as full lactation when $\geq 90 \%$ of the infants' daily energy intake came from breast milk.

Estimates of sun exposure included questions regarding preference for sun or shade when outdoors in summer (always in the sun, both sun and shade or always in the shade) according to the method of Burgaz et al. ${ }^{(13)}$, as previously 
described $^{(23)}$. Winter included months from November to April $(=1)$ and summer included months from May to October $(=2)$. Women were also asked to report travels to southern latitudes during the previous 6 months before baseline. Southern latitude was defined as a location below latitude $35^{\circ} \mathrm{N}$, where cutaneous synthesis of vitamin D is possible all year round ${ }^{(11)}$. Skin types were defined using the Fitzpatrick scale ( $\mathrm{I}=$ always burns, never tans, II = usually burns, tans with difficulty, III = sometimes burns mildly, tans gradually, IV = rarely burns, tans easily) $)^{(24)}$.

Dietary intake of vitamin D was estimated using 4-d food diaries at 4 and 12 months postpartum, as described elsewhere $^{(23)}$. Women were asked to record all food and drinks consumed as precisely as possible on 4 consecutive days with at least 1 non-working day and a preferred start no later than 1 week after the study visit. Both oral information and written information on how to fill in the food diary were given. Women were asked to report the amounts of food items consumed using household measures, weight in $g$ or using photographs of different portion sizes used in the Swedish portion guide 'Matmallen'(25). Women were also asked not to change their diet. Women were contacted if any ambiguities were noted in their foods diaries. Dietary intake was calculated using Dietist XP, version 3.1 (The National Food Agency food database version 2009-11-10; Kost och näringsdata). Details of use, frequency, amount and brand of supplements containing vitamin D were also requested at baseline and at 4 and 12 months postpartum.

Each woman rated her physical activity on a scale between 1 and 10 , as previously described ${ }^{(23)}$. Women were informed that 1 indicated a sedentary lifestyle, 5 a few long walks each week and 10 exercise several times a week. The answer was converted to a PAL, where 1 corresponded to PAL 1.3 and 10 to PAL 2.2, respectively. In a validation study, PAL assessed using this scale was correlated $(r 0.54 ; P=0.008)$ with corresponding estimates obtained using criterion methods (i.e. the doubly-labelled water method in combination with indirect calorimetry) in twenty-two healthy Swedish pregnant women (M Löf, personal communication).

\section{Laboratory analyses}

Blood samples were protected from UVB light and centrifuged within $45 \mathrm{~min}$ after sampling at $5^{\circ} \mathrm{C}, 3800 \boldsymbol{g}$, for $9 \mathrm{~min}$ (Centrifuge CR3i, Jouan Quality System; Thermo Fisher Scientific Inc.). Serum samples were then aliquoted and stored at $-70^{\circ} \mathrm{C}$ until analysed. The analyses of serum concentrations of $25(\mathrm{OH}) \mathrm{D}$ were performed at the Central Laboratory in Malmö, Sweden. The analyses were performed in batches using liquid chromatography MS/MS (Mass spectrometer API 400; AB Sciex). The method has a measuring range of $6-450 \mathrm{nmol} / 1$ for 25 -hydroxyvitamin $\mathrm{D}_{3}$ and an inter-CV of $6 \%$ at $40 \mathrm{nmol} / 1$.

\section{Statistical analyses}

All values are presented as mean values and standard deviations, if not otherwise specified. Serum 25(OH)D concentrations at baseline, at 12 months postpartum and change in 25(OH)D concentrations between baseline and 12 months postpartum were all normally distributed.

Differences in means of serum $25(\mathrm{OH}) \mathrm{D}$ at baseline and at 12 months postpartum were analysed using paired sample $t$ test. Individual changes in serum $25(\mathrm{OH}) \mathrm{D}$ concentrations between baseline and 12 months postpartum were calculated as the value at 12 months postpartum minus the value at baseline. Repeated-measures ANOVA was used to evaluate changes in serum 25(OH)D concentrations over time (between baseline, 4 and 12 months postpartum) and changes in dietary vitamin D intake between 4 and 12 months postpartum. This statistical method was used both for the whole study population and for the populations split according to different lactation categories based on the duration of total lactation: $0-3.9,4-8.9$ and $\geq 9$ months

Univariable linear regression was used to evaluate associations between possible determinants and changes in serum 25(OH)D between baseline and 12 months postpartum. The possible determinants were duration of full lactation, duration of total lactation, baseline serum $25(\mathrm{OH}) \mathrm{D}$, season at baseline, use of vitamin D supplements at baseline, dietary intake of vitamin $\mathrm{D}$ at 4 months postpartum, change in dietary intake of vitamin D (12 months minus 4 months postpartum), use of oestrogen contraceptives at 4 months postpartum, travels to southern latitudes before baseline, preference for sun or shadow at 4 months postpartum, age, height, body weight at baseline, change in body weight (12 months postpartum minus baseline), PAL at 4 months postpartum and change in PAL (12 months minus 4 months postpartum). In the regression analyses, dietary vitamin D intake, use of hormonal contraceptives containing oestrogen, PAL and sun preference at 4 months postpartum were included, as this time point more accurately reflects the actual situation during the first 4 months postpartum than do the values at baseline. Significant determinants in the univariable regression model were further explored and visualised using paired $t$ test of differences in means of serum 25(OH)D at baseline and 12 months postpartum for each level of the determinant. Different durations of lactation were analysed in this manner, as lactation was the main determinant to be investigated. For pair-wise comparisons with $n<20$, Wilcoxon's signed rank test was used.

To identify variables that best determined changes in serum $25(\mathrm{OH}) \mathrm{D}$ during the 1 st year postpartum, duration of total lactation and the variables found to be significant in the univariable linear regression analysis were entered into multivariable regression analyses. Owing to significant collinearity between season at baseline and serum 25(OH)D at baseline, only season was used in the multivariable regression analysis, as season was assumed to be the underlying predictor. Associations between serum $25(\mathrm{OH}) \mathrm{D}$ at baseline and season at baseline were analysed using a linear regression model. As season is known to be one of the major determinants of serum $25(\mathrm{OH}) \mathrm{D}^{(11)}$, interactions were analysed between season and each of the determinants found to be significant in the univariable regression analyses.

A two-tailed $\alpha$-value of 0.05 was used as the significance level. All the analyses were carried out using SPSS Statistics Software, version 22.0 (IBM).

\section{Results}

All women were fair-skinned and Swedish-speaking. At baseline, the mean age of the seventy-eight women was 32.9 (SD 3.4) 
Table 1. Vitamin D status, dietary intake and supplement use in the participating women (Mean values and standard deviations)

\begin{tabular}{|c|c|c|c|c|c|c|}
\hline \multirow[b]{2}{*}{ Variables } & \multicolumn{2}{|c|}{2 weeks postpartum $(n 78)$} & \multicolumn{2}{|c|}{4 months postpartum ( $n 78)$} & \multicolumn{2}{|c|}{12 months postpartum ( $n 78)$} \\
\hline & Mean & SD & Mean & SD & Mean & SD \\
\hline Serum 25(OH)D (nmol/l)† & 67 & 23 & 74 & 23 & 67 & $19^{*}$ \\
\hline Vitamin $D$ intake from food $(\mu \mathrm{g} / \mathrm{d}) \dagger \ddagger$ & & & $6 \cdot 7$ & $4 \cdot 1$ & $6 \cdot 0$ & $3 \cdot 1$ \\
\hline Using vitamin D supplements (\%) & 37 & & 31 & & 18 & \\
\hline Vitamin D intake from supplements among users $(\mu \mathrm{g} / \mathrm{d}) \S$ & $7 \cdot 0$ & $8 \cdot 7$ & $5 \cdot 1$ & 4.5 & $7 \cdot 3$ & $12 \cdot 4$ \\
\hline
\end{tabular}

25(OH)D, 25-hydroxyvitamin D.

${ }^{*} P<0.05$, significant change in serum $25(\mathrm{OH}) \mathrm{D}$ concentration over time, as analysed with repeated-measures ANOVA.

$\dagger$ Repeated-measures ANOVA tested changes over time.

$\ddagger$ Number of women who completed food diaries $=73$ at 12 months postpartum

$\S$ Number of women using vitamin D supplement at 2 weeks (twenty-nine), 4 months (twenty-four) and 12 months (fourteen) postpartum.

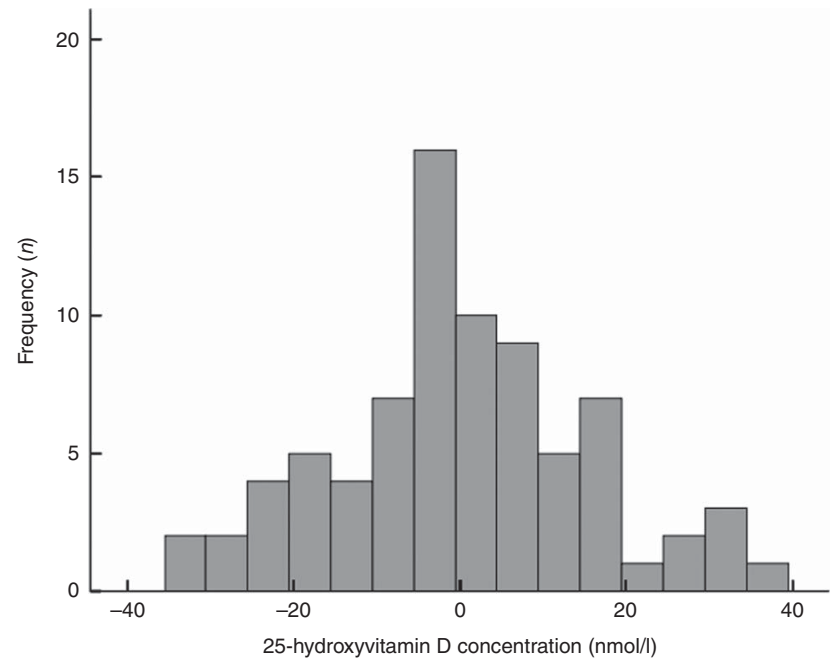

Fig. 1. Change in serum concentrations of 25-hydroxyvitamin $D$ between baseline (2 weeks postpartum) and 12 months postpartum, as analysed with the paired sample $t$ test.

years and mean height was $168.5(\mathrm{sD} 6 \cdot 3) \mathrm{cm}$. Their mean body weight was $70 \cdot 2$ (SD 9.4) $\mathrm{kg}$ and mean BMI was 24.8 (sD $3 \cdot 1) \mathrm{kg} / \mathrm{m}^{2}$. At 12 months postpartum, mean body weight was $65 \cdot 3$ (sD 8.9) kg and mean BMI was $23 \cdot 1$ (sD $3 \cdot 0) \mathrm{kg} / \mathrm{m}^{2}$. Mean body weight change between 2 weeks and 12 months postpartum was $-5 \cdot 3$ (sD $4 \cdot 3) \mathrm{kg}(P=0 \cdot 000)$. Parity ranged from 0 to 2 , and half of the women were nulliparous. In total, $79 \%$ of the women had studied for at least 3 years at university level. None of the women were smoking at baseline, and $4 \%$ of them smoked at 12 months postpartum. None of the women were using oestrogen contraceptives at baseline, $5 \%$ at 4 months postpartum and $8 \%$ at 12 months postpartum.

Median duration of full lactation was $5 \cdot 0$ (Q1-Q3 3.0-6.1) months, and the median duration of total lactation was $8 \cdot 1$ (Q1-Q3 6.8-10.4) months. At 2 weeks postpartum, $91 \%$ of the women were fully lactating and $99 \%$ were lactating to some extent. At 4 months postpartum, $69 \%$ of the women were fully lactating and $87 \%$ were lactating to some extent. At 12 months postpartum, none of the women were fully lactating and $17 \%$ of the women were lactating to some extent.
Table 1 shows the means of vitamin D status, dietary intake and supplement use during the 1st year postpartum. There was no significant change in serum $25(\mathrm{OH}) \mathrm{D}(-0.2$ (SD 15) nmol/l) concentrations between baseline and 12 months postpartum (range in change -33 to $+38 \mathrm{nmol} / \mathrm{l}$ ) (Fig. 1). Repeatedmeasures ANOVA showed a significant change in serum $25(\mathrm{OH}) \mathrm{D}$ concentration over time $(P=0 \cdot 048)$. No significant interaction was found between change in serum $25(\mathrm{OH}) \mathrm{D}$ concentration over time and lactation category. At baseline, $24 \%$ of the women had serum $25(\mathrm{OH}) \mathrm{D}$ concentrations $<50 \mathrm{nmol} / \mathrm{l}$ and $69 \%$ had serum 25(OH)D concentrations $<75 \mathrm{nmol} / \mathrm{l}$. Table 2 shows the percentages of women with serum 25(OH)D concentrations $<30,<50$ and $<75 \mathrm{nmol} / 1$ and the variation between summer and winter. The majority of women, $76 \%$ ( $n$ 59), remained in the same category of vitamin $\mathrm{D}$ status $(<30,30-50, \geq 50 \mathrm{nmol} / \mathrm{l})$ at 12 months postpartum as they were at baseline. Of the remaining women, half were cross-categorised from insufficient to sufficient and half were cross-categorised in the opposite direction

Mean total intake of vitamin $\mathrm{D}$, including both diet and supplements, was $8 \cdot 1$ (sD 5.1) $\mu \mathrm{g} / \mathrm{d}$ at 4 months postpartum and $7.4(\mathrm{SD} 6.7) \mu \mathrm{g} / \mathrm{d}$ at 12 months postpartum. Mean dietary vitamin $\mathrm{D}$ intake and intake from supplements are shown separately in Table 1 . No change in dietary vitamin D intake over time was observed. At baseline, $37 \%$ of the women were using vitamin D-containing supplements, but only $18 \%$ used supplements at 12 months postpartum.

Significant determinants for the change in serum concentrations of $25(\mathrm{OH}) \mathrm{D}$ between baseline and 12 months postpartum in univariable linear regression analyses were as follows: travels to southern latitudes during the last 6 months before the baseline measurement $(P=0 \cdot 030)$, use of oestrogen contraceptives at 4 months postpartum $(P=0 \cdot 001)$, use of vitamin D supplements at baseline $(P=0.019)$, age $(P=0.008)$, serum $25(\mathrm{OH}) \mathrm{D}$ concentrations at baseline $(P=0.000)$ and season at baseline $(P=0.003)$ (Table 3). Duration of full or total lactation was not associated with the changes in mean serum $25(\mathrm{OH}) \mathrm{D}$ concentrations during the 1st year postpartum.

Results from the paired sample $t$ test, unless otherwise stated in Table 4, showed that in women who had travelled to southern latitudes during the last 6 months before baseline the mean serum $25(\mathrm{OH}) \mathrm{D}$ concentration decreased significantly between baseline and 12 months postpartum $(P=0.033)$. 
Table 2. Percentages of women with serum concentrations of 25 -hydroxyvitamin $\mathrm{D}(25(\mathrm{OH}) \mathrm{D})<30,50$ and $75 \mathrm{nmol} / /$ at baseline and 12 months postpartum, respectively (Numbers and percentages)

\begin{tabular}{|c|c|c|c|c|c|c|}
\hline & \multicolumn{6}{|c|}{ Serum concentrations of $25(\mathrm{OH}) \mathrm{D}$} \\
\hline & \multicolumn{2}{|c|}{$<30 \mathrm{nmol} / \mathrm{l}$} & \multicolumn{2}{|c|}{$<50 \mathrm{nmol} / \mathrm{l}$} & \multicolumn{2}{|c|}{$<75 \mathrm{nmol} / \mathrm{l}$} \\
\hline & $n$ & $\%$ & $n$ & $\%$ & $n$ & $\%$ \\
\hline \multicolumn{7}{|l|}{ Baseline* } \\
\hline All & 1 & 1 & 19 & 24 & 51 & 65 \\
\hline Wintert & 1 & 1 & 11 & 31 & 29 & 83 \\
\hline Summerł & 0 & 0 & 8 & 19 & 22 & 51 \\
\hline \multicolumn{7}{|c|}{12 months postpartum } \\
\hline All & 1 & 1 & 16 & 21 & 54 & 69 \\
\hline Wintert & 1 & 1 & 10 & 27 & 30 & 81 \\
\hline Summerł & 0 & 0 & 6 & 15 & 24 & 59 \\
\hline
\end{tabular}

* Baseline was at 2 weeks postpartum.

† Winter was defined as November to April.

‡ Summer was defined as May to October.

Table 3. Univariable and multivariable linear regression investigating lactation and other determinants of changes in serum concentrations of 25-hydroxyvitamin $\mathrm{D}(25(\mathrm{OH}) \mathrm{D})$ between 2 weeks and 12 months postpartum

( $\beta$-Coefficients, standard errors and coefficient of determination)

\begin{tabular}{|c|c|c|c|c|c|c|c|c|}
\hline \multirow[b]{2}{*}{ Variables } & \multicolumn{4}{|c|}{ Univariable linear regression $(n 78)$} & \multicolumn{4}{|c|}{ Multivariable linear regression $(n 78)$} \\
\hline & $\beta$ & $\mathrm{SE}$ & $P$ & $R^{2}$ & $\beta$ & $\mathrm{SE}$ & $P$ & Adjusted $R^{2}$ \\
\hline Total lactation (months) & -0.61 & 0.50 & 0.272 & 0.019 & $0 \cdot 10$ & 0.50 & 0.846 & 0.373 \\
\hline Season* ${ }^{*}$ & $-9 \cdot 36$ & 3.35 & 0.007 & 0.093 & -8.87 & 3.06 & 0.005 & \\
\hline Use of oestrogen contraceptives $₫ \S$ & $25 \cdot 79$ & 7.36 & 0.001 & 0.139 & $18 \cdot 30$ & $7 \cdot 21$ & 0.013 & \\
\hline Use of vitamin D supplements* $\S$ & $-10 \cdot 63$ & 3.41 & 0.003 & 0.113 & -9.44 & 3.06 & 0.003 & \\
\hline Travels to southern latitudes\|§ & -10.75 & 4.87 & 0.030 & 0.060 & $-6 \cdot 27$ & $4 \cdot 20$ & 0.140 & \\
\hline Age (years) & -1.33 & 0.49 & 0.008 & 0.088 & -0.80 & 0.47 & 0.090 & \\
\hline $25(\mathrm{OH}) \mathrm{D}$, baseline $(\mathrm{nmol} / \mathrm{l})$ & -0.38 & 0.06 & 0.000 & 0.313 & & & & \\
\hline Full lactation (months) & -0.74 & 0.78 & 0.344 & 0.012 & & & & \\
\hline Dietary intake of vitamin $D(\mu \mathrm{g} / \mathrm{d}) \ddagger$ & 0.56 & 0.47 & 0.244 & 0.023 & & & & \\
\hline Change in dietary intake of vitamin D $(\mu \mathrm{g} / \mathrm{d}) \uparrow$ & 0.78 & 0.42 & 0.067 & 0.059 & & & & \\
\hline Height, baseline $(\mathrm{cm})$ & 0.01 & 0.27 & 0.979 & 0.000 & & & & \\
\hline Body weight, baseline $(\mathrm{kg})$ & -0.18 & 0.018 & 0.340 & 0.012 & & & & \\
\hline Body weight change $(\mathrm{kg})^{\star \star}$ & 0.58 & 0.41 & 0.159 & 0.026 & & & & \\
\hline PAL $\ddagger$ & 0.73 & $10 \cdot 44$ & 0.945 & 0.008 & & & & \\
\hline Change in PAL & -4.82 & 9.35 & 0.607 & 0.004 & & & & \\
\hline Sun preference $† \dagger \dagger$ & 3.34 & $5 \cdot 42$ & 0.540 & 0.005 & & & & \\
\hline
\end{tabular}

PAL, physical activity level.

* At baseline, 2 weeks after delivery.

$\dagger 1$ = Winter, 2 = summer.

$\ddagger$ At 4 months postpartum.

$\S 0=$ No, $1=$ yes.

II Travels to latitude $35^{\circ}$ North or further during the last 6 months before baseline measurement

II Between 4 and 12 months postpartum.

** Between baseline and 12 months postpartum

t† 1 = preference for staying in shade, or sun and shade, 2 =preference for staying in the sun.

Moreover, in women using vitamin D supplements at baseline, mean serum concentrations of $25(\mathrm{OH}) \mathrm{D}$ decreased significantly between baseline and 12 months postpartum $(P=0 \cdot 011)$. Only $8 \%$ of the women ( $n$ 6) were using vitamin $\mathrm{D}$ supplements throughout the whole study. No significant change in mean serum $25(\mathrm{OH}) \mathrm{D}$ concentration was found in these women during the 1st year postpartum. When women were grouped according to age, women $\geq 33$ years of age had a significant decrease in mean serum $25(\mathrm{OH}) \mathrm{D}$ concentrations between baseline and 12 months postpartum $(P=0.025)$. In contrast, in women using oestrogen contraceptives at 4 months postpartum, the mean serum $25(\mathrm{OH}) \mathrm{D}$ concentration was close to be significantly increased between 4 and 12 months postpartum $(P=0.066)$.

In women with serum $25(\mathrm{OH}) \mathrm{D}$ concentrations $<50 \mathrm{nmol} / \mathrm{l}$ at baseline, the mean serum $25(\mathrm{OH}) \mathrm{D}$ concentration increased significantly between baseline and 12 months postpartum $(P=0.004)$, whereas in women with serum 25(OH)D concentrations $\geq 50 \mathrm{nmol} / \mathrm{l}$ at baseline serum $25(\mathrm{OH}) \mathrm{D}$ concentrations decreased significantly during the same period of time $(P=0.033)$. In women who had their baseline measurement during summer, a non-significant decrease in mean serum 25(OH)D concentration between baseline and 12 months postpartum was observed $(P=0.061)$, whereas in women 
Table 4. Differences in serum concentrations of 25-hydroxyvitamin D (25(OH)D) at 2 weeks and 12 months postpartum (Numbers and percentages; mean values and standard deviations) $\dagger$

\begin{tabular}{|c|c|c|c|c|c|c|}
\hline \multirow[b]{2}{*}{ Variables } & \multirow[b]{2}{*}{$n$} & \multirow[b]{2}{*}{$\%$} & \multicolumn{2}{|c|}{$25(\mathrm{OH}) \mathrm{D}$ at 2 weeks postpartum $(\mathrm{nmol} / \mathrm{l})$} & \multicolumn{2}{|c|}{$25(\mathrm{OH}) \mathrm{D}$ at 12 months postpartum $(\mathrm{nmol} / \mathrm{l})$} \\
\hline & & & Mean & SD & Mean & SD \\
\hline \multicolumn{7}{|c|}{ Duration of total lactation } \\
\hline $0-3.9$ months & $10 \ddagger$ & 13 & 65 & 10 & 70 & 6 \\
\hline 4-8.9 months & 40 & 51 & 69 & 3 & 68 & 3 \\
\hline$\geq 9$ months & 28 & 36 & 65 & 4 & 65 & 3 \\
\hline \multicolumn{7}{|c|}{ Travels to southern latitudes§ } \\
\hline Yes & $11 \neq$ & 14 & 81 & 19 & $71^{*}$ & 19 \\
\hline No & 67 & 86 & 65 & 23 & 66 & 19 \\
\hline \multicolumn{7}{|c|}{ Use of vitamin D supplements\|l } \\
\hline Yes & 29 & 37 & 75 & 19 & $68^{*}$ & 16 \\
\hline No & 49 & 63 & 63 & 24 & 66 & 21 \\
\hline \multicolumn{7}{|c|}{ Use of oestrogen contraceptives $\mathbb{1}$} \\
\hline Yes & $4 \ddagger$ & 5 & 52 & 27 & 76 & 24 \\
\hline No & 74 & 95 & 68 & 22 & 66 & 19 \\
\hline \multicolumn{7}{|l|}{ Seasonll†† } \\
\hline Summer & 43 & 55 & 74 & 24 & 70 & 22 \\
\hline Winter & 35 & 45 & 58 & 18 & $63^{*}$ & 15 \\
\hline \multicolumn{7}{|l|}{ Age } \\
\hline$<33$ years & 45 & 58 & 70 & 24 & 70 & 18 \\
\hline$\geq 33$ years & 33 & 42 & 67 & 22 & $62^{*}$ & 19 \\
\hline \multicolumn{7}{|c|}{ Baseline serum 25(OH)D } \\
\hline$<50 \mathrm{nmol} / \mathrm{l}$ & $19 \ddagger$ & 24 & 40 & 5 & $52^{*}$ & 16 \\
\hline$\geq 50 \mathrm{nmol} / \mathrm{l}$ & 59 & 76 & 76 & 19 & $72^{*}$ & 17 \\
\hline
\end{tabular}

${ }^{*} P<0.05$, change in serum concentrations of $25(\mathrm{OH}) \mathrm{D}$ between 2 weeks and 12 months postpartum was significant.

$\dagger$ Statistical analyses performed by paired sample $t$ test within each category of exposure variables.

¥ Wilcoxon's ranked test was used to test differences between groups.

$\S$ Travels to latitude $35^{\circ}$ North or below during the last 6 months before baseline.

II At baseline, 2 weeks postpartum.

II At 4 months postpartum.

†† Summer $=$ May to October, Winter $=$ November to April.

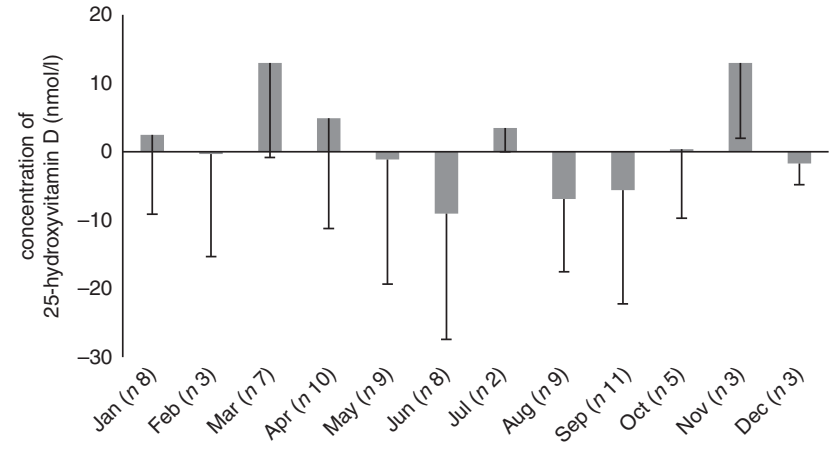

Fig. 2. Change in serum concentrations of 25-hydroxyvitamin $D$ between baseline ( 2 weeks postpartum) and 12 months postpartum, according to month at baseline. Values are means and standard deviations.

having their baseline measurement during winter a significant increase in serum $25(\mathrm{OH}) \mathrm{D}$ concentrations was observed between baseline and 12 months postpartum $(P=0.048)$ (Fig. 2). A significant relationship between season at baseline and serum $25(\mathrm{OH}) \mathrm{D}$ concentration at baseline was observed $(P=0 \cdot 001)$

In the multivariable regression analysis, including duration of total lactation and the significant determinants from the univariable regression model, use of oestrogen contraceptives, use of vitamin D supplements at baseline and season at baseline were significantly related to the changes in serum $25(\mathrm{OH}) \mathrm{D}$ concentrations between baseline and 12 months postpartum (Table 3). The model explained $37 \%$ of the variation in the change in serum concentrations of $25(\mathrm{OH}) \mathrm{D}$ between baseline and 12 months postpartum. Interactions among the determinants season and travels to southern latitudes, season and use of vitamin D supplements, season and age and season and use of oestrogen contraceptives and their combined effects on changes in serum $25(\mathrm{OH}) \mathrm{D}$ concentrations were evaluated, but no significant interactions were observed.

\section{Discussion}

This is the first study to investigate changes in serum concentrations of $25(\mathrm{OH}) \mathrm{D}$ during the 1 st year postpartum and the determinants of these changes in women in Sweden. The main finding was that mean serum $25(\mathrm{OH}) \mathrm{D}$ concentrations did not change between 2 weeks and 12 months postpartum, and no relationship was found between duration of lactation and changes in serum 25(OH)D concentrations during the 1st year postpartum. The major determinants for the variation in changes in serum concentrations of $25(\mathrm{OH}) \mathrm{D}$ postpartum were use of vitamin D supplements, use of oestrogen contraceptives and season.

Postpartum, it may be speculated that maternal vitamin D status decreases due to transfer of vitamin $\mathrm{D}$ from mother to 
child through breast milk ${ }^{(8)}$. This theory is not supported by the findings of our study. Specker et al. ${ }^{(22)}$ also did not find any relationship between the first 6 months of lactation and changes in serum $25(\mathrm{OH}) \mathrm{D}$ concentration or between lactation status and serum 25(OH)D concentration at 12 months postpartum. In addition, Møller et $a l^{(21)}$ observed no association between lactation at 2 weeks and 4 and 9 months postpartum and serum $25(\mathrm{OH}) \mathrm{D}$ concentrations. This suggests that serum $25(\mathrm{OH}) \mathrm{D}$ postpartum is not influenced by lactation to any major extent, at least not in women in Nordic countries or in North America. In contrast, Narchi et al. ${ }^{(8)}$ observed a significant decrease in serum 25(OH)D concentrations during the first 6 months postpartum among lactating women in the United Arab Emirates, and their study population differed from ours - for example, the majority of women in their study had their head and arms covered and represented several different ethnic groups. This might, in part, explain the different findings ${ }^{(8)}$. In addition, the women in the study by Narchi et al. ${ }^{(8)}$ were exclusively breast-feeding for a longer period than the women in our study.

Women using vitamin D supplements at baseline had larger decreases in serum $25(\mathrm{OH}) \mathrm{D}$ concentrations during the 1 st year postpartum than women not using vitamin D supplements. This could be explained by the higher mean $25(\mathrm{OH}) \mathrm{D}$ at baseline among supplement users than among non-users. In addition, fewer women were using vitamin D supplements at 12 months postpartum (18\%) compared with baseline (37\%). Vitamin D supplement intake has previously been shown to be one of the major determinants of serum $25(\mathrm{OH}) \mathrm{D}$ concentrations ${ }^{(13,26-28)}$. This study has shown that use of vitamin D supplements is also related to changes in serum $25(\mathrm{OH}) \mathrm{D}$ concentrations postpartum.

The observed positive relationship between use of oestrogen contraceptives and changes in serum $25(\mathrm{OH}) \mathrm{D}$ concentration during the 1st year postpartum needs to be handled with care, as only $5 \%$ (four women) were using oestrogen contraceptives at 4 months postpartum. However, the observation supports previous findings from non-lactating women where use of oestrogen contraceptives was shown to be associated with higher serum $25(\mathrm{OH}) \mathrm{D}$ concentrations ${ }^{(21,26,29,30)}$. In agreement with our results, where serum $25(\mathrm{OH}) \mathrm{D}$ tended to increase over $20 \mathrm{nmol} / 1$ in women who started to use oestrogen contraceptives, Harris et al. ${ }^{(29)}$ found a decrease in serum $25(\mathrm{OH}) \mathrm{D}$ concentration of over $20 \mathrm{nmol} / \mathrm{l}$ in women who discontinued oestrogen contraceptive use. During lactation, oestrogen levels are low and amenorrhoea may occur ${ }^{(31,32)}$. The theory behind the observed relationship between $25(\mathrm{OH}) \mathrm{D}$ concentration and oestrogen is that oestrogen may increase the vitamin D-binding protein $^{(29,30,33)}$. This increase would, in turn, decrease the free concentrations of all vitamin D metabolites and result in an overall increase in the circulating levels of $25(\mathrm{OH}) \mathrm{D}^{(30)}$.

A significant decrease in serum $25(\mathrm{OH}) \mathrm{D}$ concentration postpartum was found in the univariable analyses in women who had travelled to southern latitudes before their baseline measurement, but not in those who had not been travelling. This might be explained by the higher baseline mean serum $25(\mathrm{OH}) \mathrm{D}$ in women who had travelled before baseline compared with women who had not recently travelled. During the 1st year postpartum, only two women who travelled before their baseline measurement travelled again. This might explain the decrease in serum 25(OH)D concentration. Previous studies have shown that travel to southern latitudes is a determinant of serum $25(\mathrm{OH}) \mathrm{D}$ concentration during pregnancy ${ }^{(23,34)}$ as well as in non-pregnant and non-lactating women ${ }^{(13,26)}$, but, until now, not in lactating women. Other variables of sun exposure have been reported to be major determinants of serum $25(\mathrm{OH}) \mathrm{D}$ concentration ${ }^{(19,27,35)}$. Overall, exposure to sunlight is the primary source for vitamin $\mathrm{D}^{(1,36)}$, but in Gothenburg on $57^{\circ}$ North cutaneous production of vitamin D is only possible between April and September ${ }^{(11)}$. This is probably why travel to southern latitudes, where cutaneous vitamin $\mathrm{D}$ production is possible all year round, is related to a higher vitamin D status.

The significant increase in serum $25(\mathrm{OH}) \mathrm{D}$ concentrations during the 1 st year postpartum in women with serum $25(\mathrm{OH}) \mathrm{D}$ $<50 \mathrm{nmol} / \mathrm{l}$ at baseline, but not in women with serum 25(OH)D $\geq 50 \mathrm{nmol} / \mathrm{l}$ at baseline, may be explained by the regression to the mean phenomena. Whether this discrepancy between the subgroups is explained by other factors, such as a change in sun exposure, can only be speculated. Both these possible explanations may also account for the relationship found between changes in serum $25(\mathrm{OH}) \mathrm{D}$ concentration postpartum and season at baseline. Women giving birth during winter had a significant increase in serum 25(OH)D concentrations during the 1st year postpartum, whereas no such relationship was found in women giving birth during summer.

Serum 25(OH)D concentration is known to be lower in obese individuals than in normal-weight individuals ${ }^{(2,14)}$. In this study, $22.1 \%$ of the women were overweight, but only $2.6 \%$ were obese at 12 months postpartum. However, no relationships were found between changes in serum $25(\mathrm{OH}) \mathrm{D}$ concentration and BMI or body weight during the 1 st year postpartum. The mean BMI at 12 months postpartum was $23.1 \mathrm{~kg} / \mathrm{m}^{2}$ and is lower than the corresponding value in the general population $\left(25 \cdot 1 \mathrm{~kg} / \mathrm{m}^{2}\right)^{(37)}$. Mean age at baseline was 32.9 years, which is slightly higher than the comparable national data for pregnant women of 30.8 years $^{(38)}$. In total, $80 \%$ of the women had $\geq 3$ years of education at university level, compared with $37 \%$ in the general Swedish population of women in the same age group $^{(39)}$. In total, $88 \%$ of the women were lactating to some extent at 4 months postpartum, compared with only $75 \%$ of the women in the whole country ${ }^{(7)}$. Earlier studies have found that women with higher education breast-feed for a longer period $^{(40)}$. As the women in this study weighed less, had higher education, lactated to a greater extent and actively chose to participate in the study, they may be more health conscious than the general population.

Limitations of the present study include the small sample size and the homogeneous study population, which make it difficult to generalise the results. Furthermore, the small number of women using oestrogen contraceptives means that these results need to be carefully interpreted. The strengths of the study are that it is one of very few studies examining changes in serum concentrations of $25(\mathrm{OH}) \mathrm{D}$ postpartum overall. This is the first study examining lactation as well as other determinants of serum $25(\mathrm{OH}) \mathrm{D}$ concentration at northern latitudes, where cutaneous production is not possible all 
year round. In addition, we examined a broad spectrum of possible determinants and had a long-term follow-up throughout a whole year, covering all seasons.

In conclusion, in this population of Swedish women, mean serum concentration of $25(\mathrm{OH}) \mathrm{D}$ did not change between 2 weeks and 12 months postpartum, and no relationship was found between duration of lactation and changes in serum $25(\mathrm{OH}) \mathrm{D}$ concentration during the 1 st year postpartum. Instead, the main determinants of the variation in changes in serum $25(\mathrm{OH}) \mathrm{D}$ during the 1 st year postpartum were use of vitamin D supplements, use of oestrogen contraceptives and season.

\section{Acknowledgements}

The authors thank all the participants and their families. The authors also thank technical assistants Elisabeth Gramatkovski and Birgitta Arvidsson and research nurse Anna Folino for their help with data collection and handling and Ann Laskey for valuable comments.

This study was supported by The Swedish Research Council Formas (No. 2007-398 and 2009-1504) (H. A.); The Graduate School Environment and Health (H. A.); The Swedish Nutrition Foundation (P. B.); Wilhelm \& Martina Lundgrens Vetenskapsfond (P. B.); Magnus Bergvall Foundation (H. A.); Fredrik and Ingrid Thuring Foundation (H. A.); Olof Johannisson Foundation (H. A.); The Swedish Society of Medicine (H. A.); Swedish Society for Medical Research (H. A.); Sahlgrenska University Hospital Foundation (H. A.); Gustaf V and Queen Victoria's Freemason Foundation (H. A.); and Kvinnor \& Hälsa Foundation (H. A.). No funders had any role in the design, analysis or writing of this article.

P. B. is the main author, but all authors contributed to the text. P. B. and H. A. made substantial contributions to data collection and laboratory work and L. B. and M. B. to the data handling. H. A. designed the study and P. B., A. W. and H. A. made substantial contribution to the statistical analyses.

None of the authors has any conflicts of interest to declare.

\section{References}

1. Nordic Council of Ministers (2014) Nordic Nutrition Recommendations - Integrating Nutrition and Physical Activity, 5th ed., vol. 2014:002. Copenhagen: Norden.

2. Holick MF (2007) Vitamin D deficiency. N Engl J Med 357, 266-281.

3. Salle BL, Delvin EE, Lapillonne A, et al. (2000) Perinatal metabolism of vitamin D. Am J Clin Nutr 71, 1317s-1324s.

4. Institute of Medicine (IOM) (1997) Dietary Reference Intakes for Calcium, Phosphorus, Magnesium, Vitamin $D$ and Fluoride. Washington, DC: National Academies Press.

5. Horta BLBR, Martines JC \& Victoria CG (2007) Evidence on the Long-Term Effects of Breastfeeding - Systematic Reviews and Meta-Analysis. Geneva: WHO.

6. Butte NF \& King JC (2005) Energy requirements during pregnancy and lactation. Public Health Nutr 8, 1010-1027.

7. Statistics Sweden (2014) Breast-Feeding and Smoking Habits Among Parents of Infants Born in 2012. Stockholm: The National Board of Health and Welfare.
8. Narchi H, Kochiyil J, Zayed R, et al. (2010) Maternal vitamin D status throughout and after pregnancy. J Obstet Gynaecol 30, 137-142.

9. National Food Agency (2012) Riksmaten 2010-11. Food-and Nutrition Intake in Adults in Sweden. Uppsala, Sweden: National Food Agency.

10. IOM (2010) Dietary Reference Intakes for Calcium and Vitamin D. Washington, DC: National Academies Press.

11. Tsiaras WG \& Weinstock MA (2011) Factors influencing vitamin D status. Acta Derm Venereol 91, 115-124.

12. Holick MF (1995) Environmental factors that influence the cutaneous production of vitamin D. Am J Clin Nutr $\mathbf{6 1}$, 638s-645s.

13. Burgaz A, Akesson A, Oster A, et al. (2007) Associations of diet, supplement use, and ultraviolet $\mathrm{B}$ radiation exposure with vitamin $\mathrm{D}$ status in Swedish women during winter. Am J Clin Nutr 86, 1399-1404.

14. Thuesen B, Husemoen L, Fenger M, et al. (2012) Determinants of vitamin D status in a general population of Danish adults. Bone 50, 605-610.

15. Dawson-Hughes B, Heaney RP, Holick MF, et al. (2005) Estimates of optimal vitamin D status. Osteoporos Int 16, 713-716.

16. Challa A, Ntourntoufi A, Cholevas V, et al. (2005) Breastfeeding and vitamin D status in Greece during the first 6 months of life. Eur J Pediatr 164, 724-729.

17. Andiran N, Yordam N \& Ozon A (2002) Risk factors for vitamin D deficiency in breast-fed newborns and their mothers. Nutrition 18, 47-50.

18. Czech-Kowalska J, Latka-Grot J, Bulsiewicz D, et al. (2014) Impact of vitamin D supplementation during lactation on vitamin $\mathrm{D}$ status and body composition of mother-infant pairs: a MAVID randomized controlled trial. PLOS ONE 9, e107708.

19. Dawodu A, Davidson B, Woo JG, et al. (2015) Sun exposure and vitamin D supplementation in relation to vitamin D status of breastfeeding mothers and infants in the global exploration of human milk study. Nutrients 7, 1081-1093.

20. Dahlman I, Gerdhem P \& Bergstrom I (2013) Vitamin D status and bone health in immigrant versus Swedish women during pregnancy and the post-partum period. I Musculoskelet Neuronal Interact 13, 464-469.

21. Møller UK, Streym S, Heickendorff L, et al. (2012) Effects of $25 \mathrm{OHD}$ concentrations on chances of pregnancy and pregnancy outcomes: a cohort study in healthy Danish women. Eur J Clin Nutr 66, 862-868.

22. Specker BL, Tsang RC \& Ho ML (1991) Changes in calcium homeostasis over the first year postpartum: effect of lactation and weaning. Obstet Gynecol 78, 56-62.

23. Brembeck P, Winkvist A \& Olausson H (2013) Determinants of vitamin $\mathrm{D}$ status in pregnant fair-skinned women in Sweden. Br J Nutr 110, 856-864.

24. Astner S \& Anderson RR (2004) Skin phototypes 2003. J Invest Dermatol 122, xxx-xxxi.

25. National Food Agency (1997) Matmallen. Uppsala: National Food Agency.

26. Hedlund L, Brembeck P \& Olausson H (2013) Determinants of vitamin D status in fair-skinned women of childbearing age at northern latitudes. PLOS ONE 8, e60864.

27. Andersen R, Brot C, Jakobsen J, et al. (2013) Seasonal changes in vitamin $\mathrm{D}$ status among Danish adolescent girls and elderly women: the influence of sun exposure and vitamin D intake. Eur J Clin Nutr 67, 270-274.

28. Cashman KD, Hill TR, Lucey AJ, et al. (2008) Estimation of the dietary requirement for vitamin D in healthy adults. Am J Clin Nutr 88, 1535-1542. 
29. Harris SS \& Dawson-Hughes B (1998) The association of oral contraceptive use with plasma 25-hydroxyvitamin D levels. J Am Coll Nutr 17, 282-284.

30. Sowers MR, Wallace RB, Hollis BW, et al. (1986) Parameters related to 25-OH-D levels in a population-based study of women. Am J Clin Nutr 43, 621-628.

31. McNeilly AS, Tay CC \& Glasier A (1994) Physiological mechanisms underlying lactational amenorrhea. Ann $N Y$ Acad Sci 709, 145-155.

32. Howie PW, McNeilly AS, Houston MJ, et al. (1982) Fertility after childbirth: post-partum ovulation and menstruation in bottle and breast feeding mothers. Clin Endocrinol 17, 323-332.

33. Aarskog D, Aksnes L, Markestad T, et al. (1983) Effect of estrogen on vitamin D metabolism in tall girls. $J$ Clin Endocrinol Metab 57, 1155-1158.

34. Vandevijvere S, Amsalkhir S, Van Oyen H, et al. (2012) High prevalence of vitamin $\mathrm{D}$ deficiency in pregnant women: a national cross-sectional survey. PLOS ONE 7, e43868.
35. Burgaz A, Akesson A, Michaelsson K, et al. (2009) 25-Hydroxyvitamin D accumulation during summer in elderly women at latitude 60 degrees N. J Intern Med 266, 476-483.

36. De-Regil LM, Palacios C, Ansary A, et al. (2012) Vitamin D supplementation for women during pregnancy. Cochrane Database Syst Rev 2, Cd008873.

37. Statistics Sweden (2013) BMI, Body Weight and Height - Mean Values 1988-89, 2008-2011. Stockholm: Statistics Sweden.

38. Statistics Sweden (2013) Older mothers were more common in the past. http://www.scb.se/sv_Hitta-statistik/Artiklar/Aldremammor-vanligare-forr/ (accessed April 2015).

39. Statistics Sweden (2012) Educational Attainment of the Population 2010, Corrected 2012. Stockholm: Statistics Sweden.

40. Flacking R, Nyqvist KH \& Ewald U (2007) Effects of socioeconomic status on breastfeeding duration in mothers of preterm and term infants. Eur J Public Health 17, 579-584. 